\title{
BMJ Open Effects of interorganisational information technology networks on patient safety: a realist synthesis
}

\author{
Justin Keen (D) , ${ }^{1}$ Maysam Ali Abdulwahid, ${ }^{1}$ Natalie King, ${ }^{1}$ Judy M Wright (D) , \\ Rebecca Randell (D) , ${ }^{2}$ Peter Gardner, ${ }^{3}$ Justin Waring, ${ }^{4}$ Roberta Longo, ${ }^{1}$ \\ Silviya Nikolova, ${ }^{1}$ Claire Sloan, ${ }^{1}$ Joanne Greenhalgh ${ }^{5}$
}

To cite: Keen J, Abdulwahid MA King N, et al. Effects of interorganisational information technology networks on patient safety: a realist synthesis. BMJ Open 2020;10:e036608. doi:10.1136/ bmjopen-2019-036608

- Prepublication history for this paper is available online. To view these files, please visit the journal online (http://dx.doi. org/10.1136/bmjopen-2019036608).

Received 07 January 2020 Revised 06 July 2020 Accepted 25 August 2020

Check for updates

(c) Author(s) (or their employer(s)) 2020. Re-use permitted under CC BY. Published by BMJ.

${ }^{1}$ Leeds Institute of Health Sciences, University of Leeds, Leeds, UK

${ }^{2}$ Faculty of Health Studies, University of Bradford, Bradford, UK

${ }^{3}$ School of Pharmacy and Medical Sciences, University of Bradford, Bradford, UK ${ }^{4}$ Health Services Management Centre, University of

Birmingham, Birmingham, UK

${ }^{5}$ Sociology and Social Policy,

University of Leeds, Leeds, UK

Correspondence to

Dr Justin Keen;

J.Keen@leeds.ac.uk

\section{ABSTRACT}

Objective Health services in many countries are investing in interorganisational networks, linking patients' records held in different organisations across a city or region. The aim of the systematic review was to establish how, why and in what circumstances these networks improve patient safety, fail to do so, or increase safety risks, for people living at home.

Design Realist synthesis, drawing on both quantitative and qualitative evidence, and including consultation with stakeholders in nominal groups and semistructured interviews.

Eligibility criteria The coordination of services for older people living at home, and medicine reconciliation for older patients returning home from hospital.

Information sources 17 sources including Medline, Embase, CINAHL, Cochrane Library, Web of Science, ACM Digital Library, and Applied Social Sciences Index and Abstracts.

Outcomes Changes in patients' clinical risks.

Results We did not find any detailed accounts of the sequences of events that policymakers and others believe will lead from the deployment of interoperable networks to improved patient safety. We were, though, able to identify a substantial number of theory fragments, and these were used to develop programme theories.

There is good evidence that there are problems with the coordination of services in general, and the reconciliation of medication lists in particular, and it indicates that most problems are social and organisational in nature. There is also good evidence that doctors and other professionals find interoperable networks difficult to use. There was limited high-quality evidence about safety-related outcomes associated with the deployment of interoperable networks.

Conclusions Empirical evidence does not currently justify claims about the beneficial effects of interoperable networks on patient safety. There appears to be a mismatch between technology-driven assumptions about the effects of networks and the sociotechnical nature of coordination problems.

PROSPERO registration number CRD42017073004.

\section{BACKGROUND}

Many people who live in their own homes, and who have a number of health problems,
Strengths and limitations of this study

- This is the first systematic review that seeks to explain the effects of extrahospital information technology networks on patient safety.

- The review investigates the distance between policy aspirations and realities in clinical settings.

- We were only able to test a limited set of possible explanations for the effects of networks.

- Aspects of quality appraisal rely on research team judgements: other teams might make different judgements.

Breadth of coverage was maximised, and to some extent traded off against the overall quality of included articles.

need support from a range of professionals. There is good evidence that treatment and care is often fragmented, and increases patients' safety risks. ${ }^{1-3}$ Policymakers and opinion leaders have argued that interoperable networks, which give clinicians access to patient records held in healthcare organisations across cities and regions, can help to overcome the fragmentation. ${ }^{34}$ The networks should, therefore, support safer treatment and care. ${ }^{5}$

Health services have long had many discrete information technology (IT) systems, developed by different suppliers, so that general practitioners, community nurses, pharmacists and others use different systems. From the 1980s onwards hospital departments also had their own systems for pathology, radiology, operating theatres, and so on. ${ }^{6-8}$ That is, the IT systems have also been fragmented, and in the views of policymakers also need to be integrated. ${ }^{9}{ }^{10}$ In practice, the technological task is to link the different systems together in an interoperable network that spans a geographical area, such as a city or county. The networks can be designed in different ways. At one end of a continuum, a network 
provides clinicians with 'seamless' access to systems across a locality, so that they appear as a single patient record and are easy to navigate. At the other, clinicians can access the various different systems, with their own formats, and have to learn how to navigate each one to locate the information they need. It is not clear what types of network are currently available to clinicians. Systematic review evidence about the use of, and effects of, these networks is relatively limited and mixed. ${ }^{11}{ }^{12}$ Policy thinking therefore rests largely on assumptions about the value of interoperable networks.

This article reports on the findings of a systematic review, using the realist synthesis method, of the effects of interoperable networks on patient safety, which we defined as quantified changes in patients' clinical risks. The review included all configurations of networks, and effects could be attributable to networks or to a combination of networks and users. There were two strands to the review, focused on the coordination of services, and on the reconciliation of medication information, for older people living at home. The review identified policymakers and other stakeholders' assumptions about the ways in which interoperable networks influence clinical processes and outcomes and then evaluated the extent to which evidence about actual deployments supports the assumptions (or fails to do so). ${ }^{13-16}$

The realist synthesis included structured database searches of a wide range of databases, supplementary searches and stakeholder consultation. A range of quantitative and qualitative evidence was included. The synthesis is reported according to the Preferred Reporting Items for Systematic Reviews and Meta-Analyses (PRISMA) guidelines, and is consistent with the Realist and Metanarrative Evidence Synthesis: Evolving Standards guidelines. ${ }^{17} 18$ A protocol was developed and submitted to the PROSPERO registry of systematic reviews prior to commencing the review.

\section{DESIGN}

The realist synthesis was undertaken in two discrete stages: theory development and empirical assessment. Theory development involved the development of programme theories, these being representations of the way(s) in which an intervention is intended to work. ${ }^{19-21}$ Structured database and complementary searches were undertaken to identify published theories, or fragments of theories, that is, theories which covered a part of the sequences of decisions and actions that lead from the intervention to a safety-related outcome. Stakeholder consultation is usual in realist syntheses, and in this study nominal group consultation was used to refine the initial programme theories, and to help identify appropriate populations and settings for assessment. Assessment was undertaken through structured database and complementary searches, designed to identify empirical evidence to establish whether programme theories worked in the

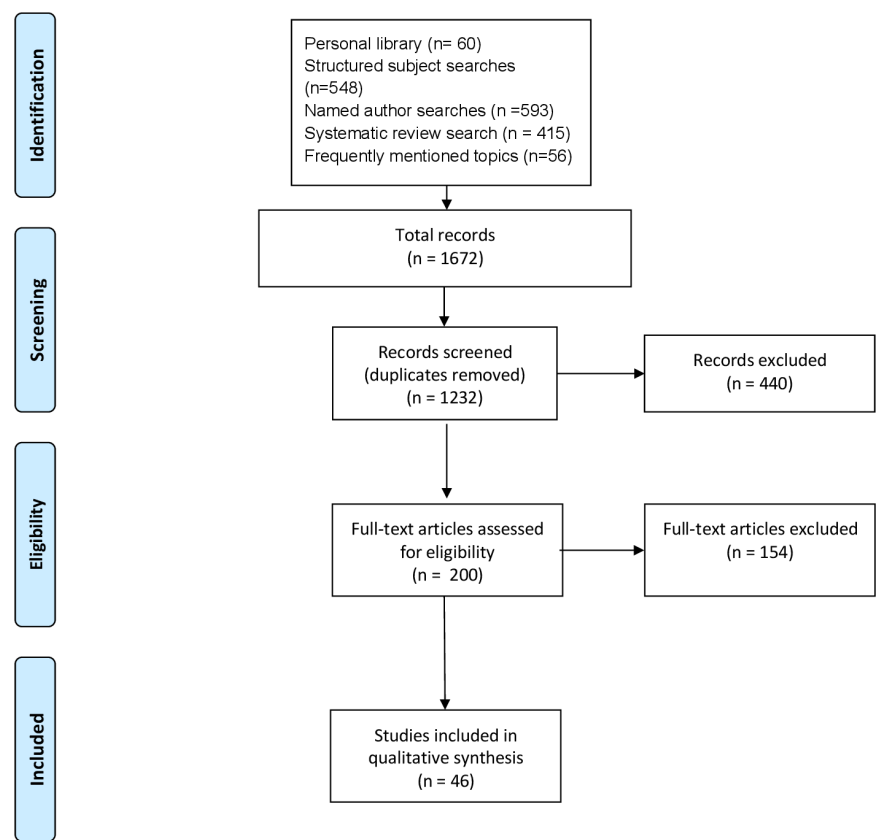

Figure 1 Theory development Preferred Reporting Items for Systematic Reviews and Meta-Analyses (PRISMA) diagram.

ways that were intended-or did not work, or worked in some other way.

\section{Theory development}

Five theory development searches were undertaken, including structured subject searches, a review of England and US government policies and official reports, named author searches (for Professors David Bates and Robert Wachter), systematic review and a Web of Science 'usage count' (articles with a high level of interest) searches (see figure 1). We were looking for statements that set out authors' reasoning about the effects of interoperable networks, which might be found in a wide range of texts, including editorials and interviews as well as journal articles and book chapters. They could be described using different terms, so we used very broad inclusion criteria and read substantial numbers of full texts. Passages where theories and fragments were described were copied into Word files, or hyperlinks created to long passages. The passages were synthesised into initial programme theories. $^{22}$

We recruited two nominal groups of national policymakers and of IT leads responsible for interoperable networks in two regions of England. Consultation with senior managers at National Health Service (NHS) Digital led us to identify six national policymakers from three different organisations (NHS Digital, NHS England, Public Health England), to give us a range of perspectives. Five IT leads for different localities in the south of England were identified purposively as leaders in implementing interoperable networks by NHS colleagues in the north of England. We had no prior links with them. The initial theories, in the form of diagrams and supporting explanatory text, were presented to the nominal groups, and also to a patient and public involvement (PPI) panel. 
ACCESS TO INFORMATION

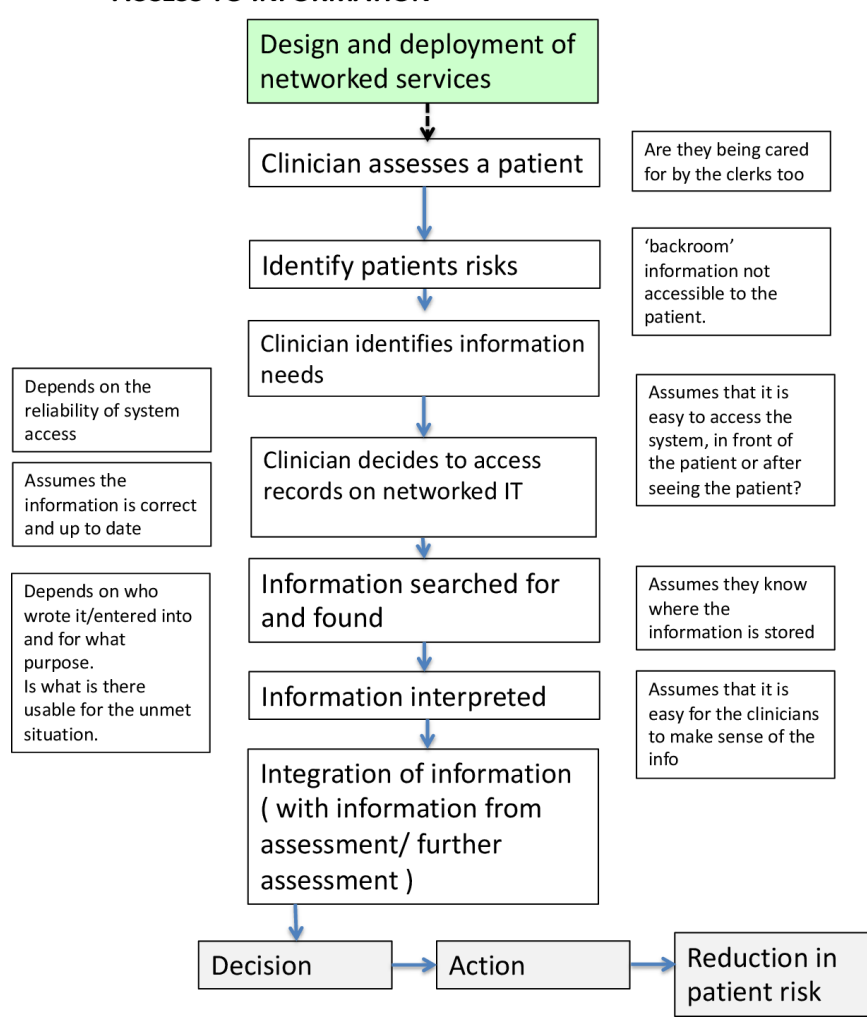

Figure 2 Main programme theory. IT, information technology.

Their members commented on the face validity of the programme theories, suggested ways in which they might be refined and indicated their priorities for evidence searches. Their comments fed into the identification and development of a main programme theory, and to inform the design of detailed evidence searches.

The nominal groups indicated that, rather than finegrained analyses of programme theories, they would value evidence about the effects on patient safety, and quality of treatment and care more generally. They observed there was little incentive to provide anything beyond functional-basic-interoperability, as many clinicians only used networks 'tactically', when they really needed information. As a result, evidence about functional interoperability would be valuable to them. They also indicated their priorities for evidence searches, leading us to settle on a single programme theory for assessment, and exploration of two functions of interoperable networks-in coordinating care across professional and organisational boundaries, and in medicine reconciliation (see figure 2). The PPI panel supported these priorities.

\section{Patient and public involvement}

The PPI panel met three times in the course of the review and contributed in the following ways:

- Their comments helped us to set priorities for the populations and settings used in the searches.

- They contributed to the interpretation of the initial findings of the evidence searches.
- They commented on our overall interpretation of our findings at the end of the review.

This being a literature review, patients were not recruited to this study. Summaries and full reports of the review have been sent to the nominal and PPI groups.

\section{Evidence searches: data sources and searches}

Searches were designed to interrogate the programme theory for two different functions of interoperable networks-the coordination of services for older people living in their own homes who were in receipt of two or more services from different organisations and, more specifically, the coordination of services for older people living in their own homes who had been prescribed medication from two or more organisations. (We focused on medicine reconciliation involving two or more lists of medications, and lists that were reconciled with a patient assessment undertaken by a clinician.) We undertook three searches for each function, focusing on the nature and extent of coordination problems (that interoperable networks might in principle help to address), on user experiences of using interoperable networks and on outcomes (defined as changes in patients' risks of harm).

The designs of the searches for each function were similar, allowing us to compare and contrast findings. All searches included the Medline database bundle 'Ovid MEDLINE and Epub Ahead of Print, In-Process \& Other Non-Indexed Citations and Daily 1946-present'. ${ }^{18}$ (Details of additional databases used in each search, and PRISMA flow diagrams are provided in separate files.) Search terms and synonyms were identified by the project team on the basis of a programme theory selected for assessment (see figure 2). All of the searches were performed and peer reviewed by information specialists (NK, JW). Structured search strategies were developing using free text words, synonyms and subject index terms organised into search concepts. Further complementary searches, including forward and backward citation searches, were also undertaken.

\section{Study selection}

Inclusion and exclusion criteria were designed for each search, with the following inclusion criteria common to all searches:

- Written in the English language.

- Published in 2000 or later. ${ }^{23}$

Articles were assessed for relevance and rigour by three reviewers (MAA, JG, JK).

Relevance was assessed pragmatically using a 'target', akin to an archery target. Articles that met all inclusion criteria were placed in the 'bullseye'. Those that only partially met the population (eg, frail older people) criteria, but met other criteria, were placed in the middle ring. Articles that did not strictly meet either population or intervention criteria, but where it was judged that they might nevertheless shed light on the mechanisms involved, were placed in the outer ring. 


\section{Data extraction and quality assessment}

For included articles, study identifiers (author, publication year, country), information about the intervention and study methods (methods used, numbers and types of participants) and the evidence itself were recorded in customised spreadsheets. In relation to rigour, critical appraisal skills programme quality assessment checklists were completed by one member of the team (MAA) and reviewed by colleagues (JK or JG) to appraise systematic reviews, narrative and cohort studies.

\section{Synthesis}

The empirical evidence for each function was used for two comparisons, namely the functions with one another, and each function with the programme theory. ${ }^{24}$ The comparison with the programme theory allowed us to identify the assumptions which were and were not supported by the evidence. ${ }^{25} 26$

\section{RESULTS}

Following study selection and assessment 46 studies were included. Many general statements were found which stated that interoperable networks would improve patient safety. For example, a 2016 report for the US Office of the National Coordinator for Health Information Technology stated that interoperable networks:

can improve... safety by improving the timelines and completeness of important patient health information. ${ }^{27}$

Similarly, a 2016 report for the NHS in England recommended that the NHS should:

...ensure interoperability as a core characteristic of NHS Digital ecosystem-to support clinical care and to promote innovation and research. ${ }^{28}$

The policy argued that the objectives for interoperability included enabling integrated workflow, service redesign and clinical decision support. We did not find any detailed accounts that described or explained how they would produce safer diagnosis, treatment and care. A substantial number of theory fragments were, though, identified. $^{1229-32}$ For example, it was argued that interoperable networks would make information available to clinicians wherever and whenever it was needed, enabling integrated workflow and clinical decision support. ${ }^{28}$ There were also statements about challenges and risks, associated with a lack of common data standards, problems with interfaces and concerns about privacy. ${ }^{22}$ These and other fragments were combined to create an initial programme theory.

\section{Evidence searches: care coordination}

Five reviews were included on the nature of coordination problems in services for older people (table 1). The hand search of King's Fund reports produced two further reviews. The reviews were conducted in different academic traditions, and used different review methods, but produced broadly similar findings. There was good evidence that coordination problems were social and organisational in nature. Leadership, organisation cultures and trust influenced the effectiveness of coordination. Communication problems were also highlighted. These were typically characterised as a combination of task failures-such as failures to pass key information about a patient to a clinical colleague-and problems with conveying messages to colleagues with different professional backgrounds. ITs were rarely mentioned as having a role in either creating or solving problems.

We included four reviews and two primary studies from the evidence searches for user experiences of interoperable networks in the adult and older population (rather than older people specifically, table 2). A forward citation search from a 2013 review of the computer-supported cooperative work literature did not yield any further articles. ${ }^{16}$ Most evidence was based on interviews, and therefore on subjective reports of behaviour rather than direct observational evidence of user experiences. Key details were missing from most reports, including information about interface characteristics and other features of the interoperable networks studied. This said, there was a consistent theme, indicating that interoperable networks were difficult to use, with problems reported in accessing networks, searching for and finding relevant information, and hence perceptions that the time costs of these activities were excessive.

Three articles were included from the searches for evidence about patient outcomes. All three were based on interviews with small samples of interviewees, reporting on experiences with networks with limited functionality. There was a common picture of difficulties encountered in accessing and using them, which led to broadly negative perceptions of their value. ${ }^{33-35}$ Five review articles were identified as relevant in a subsequent broader search, for evidence about adult patients in general (table 3). They included quantitative evidence, of variable quality, about intermediate measures including adverse event and hospital readmission rates. The results were, broadly, positive in the sense that population rates were reported to reduce, implying the possibility of reductions in patients' risks. However, there were also some negative results, and none of the reviews included any quantitative evidence about the effects of interoperable networks on patient outcomes.

\section{Evidence searches: medicine reconciliation}

For the nature of medicine reconciliation problems question, one systematic review, one other review and two observational studies were included (table 1). The overall quality of empirical evidence was reasonable. It indicated that the challenges were social and organisational in nature, the main one being that responsibility for reconciliation is not clear on the ground, particularly following discharge from hospital to home. As a result, responsibility fell between professionals, principally pharmacists, 


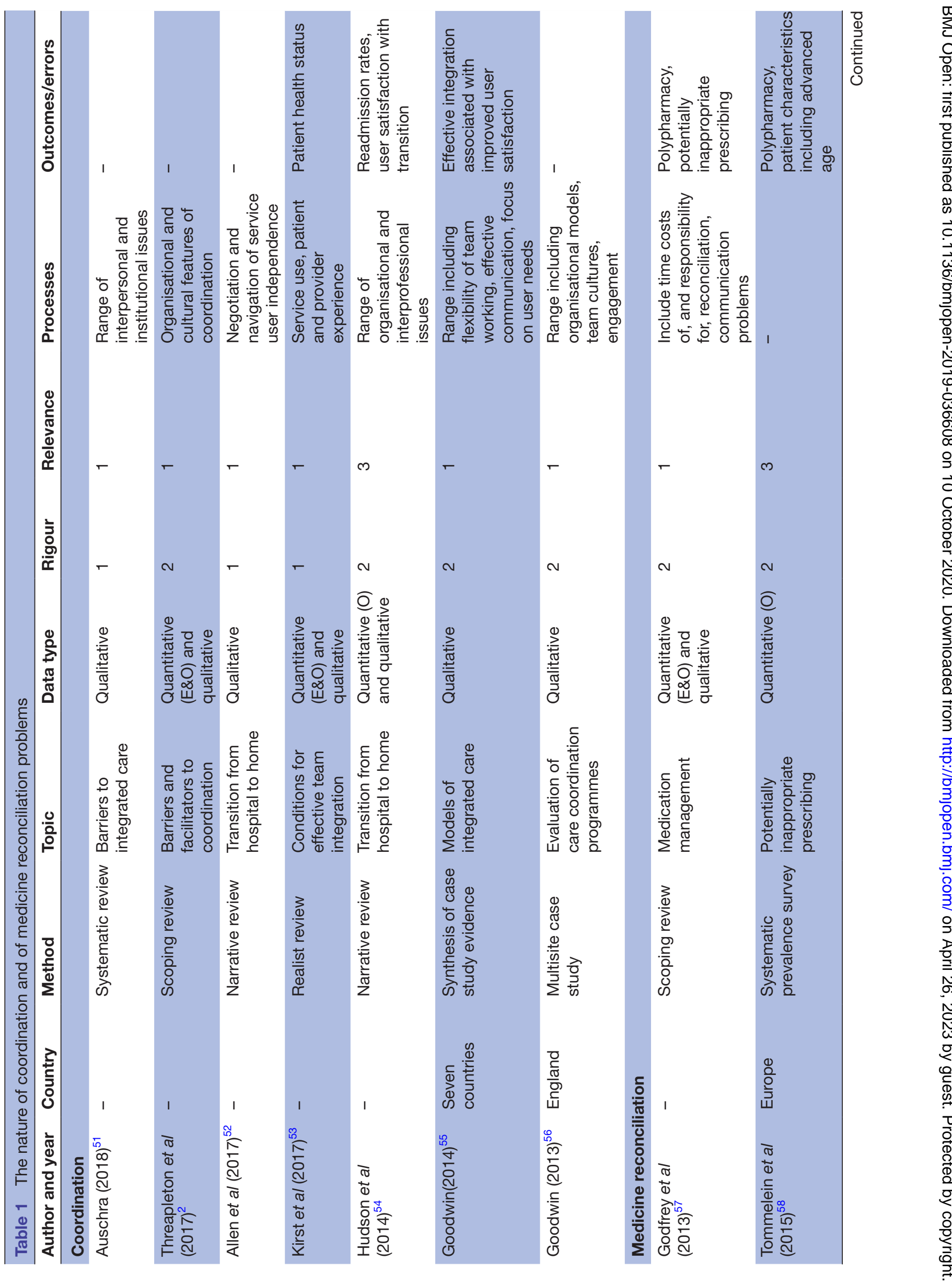




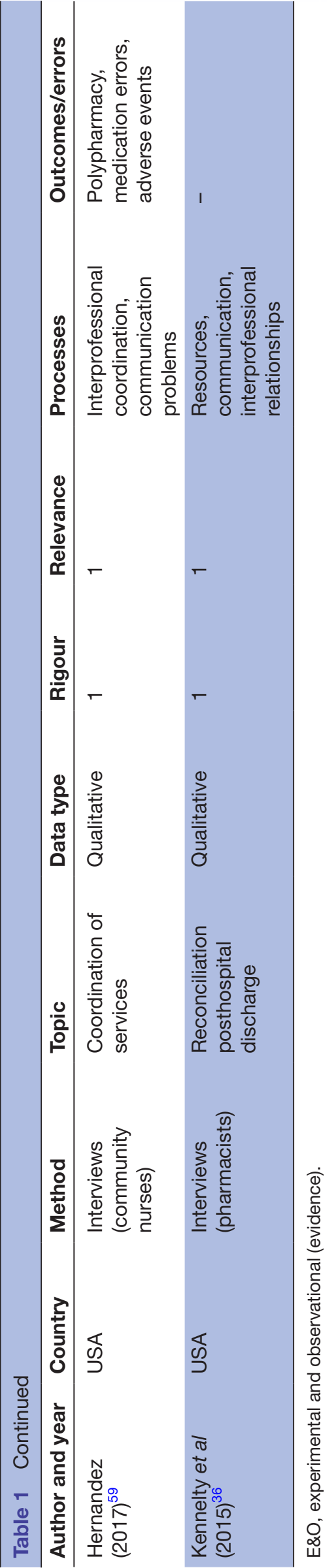

doctors and nurses. Reconciliation could also be viewed as an administrative task (rather than a safety-promoting one), and was not deemed to be important by some professionals. Communication problems emerged clearly as a theme.

Nine articles were identified that shed light on user experiences of medicine reconciliation. ${ }^{36-44}$ These were a mix of scenario-based and field-based observational studies. The search for evidence about patient outcomes did not identify any quantitative evidence about changes in patients' risks. Results about proxy outcomes-changes in reconciliation error rates-were mixed. Some articles indicated that use of an interoperable network was associated with a measurable reduction in reconciliation errors. Others reported problems with using systems, resulting in no effects on error rates.

\section{Synthesis}

We did not find any detailed published accounts that described the ways in which interoperable networks might improve patient safety (or increase patients' risks). For both functions, clinicians found that it was difficult to access networks, and to find and use relevant patient information. The evidence about outcomes, for both functions, was limited.

The programme theory assumed that information would be easy to find and use, and that patients' clinical risks would be reduced: the evidence did not support these elements of the theory. More generally, the programme theory was technology driven, assuming that the introduction of interoperable networks would lead to improved processes and outcomes.

\section{DISCUSSION}

We did not find evidence that policymakers and opinion leaders have thought through the logic of their assumptions about interoperable networks. A key assumption, seemingly widely shared, is that clinicians need access to comprehensive data on their patients, wherever it is held. This has led to the policy prescription of interoperable networks in many countries. The prescription is intuitively reasonable, but our findings indicate that the underlying reasoning is flawed.

There were four main limitations to the study. First, we did not test alternative programme theories about the effects of interoperable networks on patient safety: it is not possible to rule out plausible explanations that have not been considered by policymakers and others, and hence by us. We might, for example, have drawn on complexity or other theories, instead of the views of policymakers and opinion leaders, to develop alternative programme theories. Second, realist synthesis is still developing as a systematic review method. The elements of our method have all been reported by other teams, but in slightly different combinations in different studies. Third, the aspects of the method involved team judgements. Other research teams might, for example, 
Table 2 Coordination of services: user experiences of interoperable networks

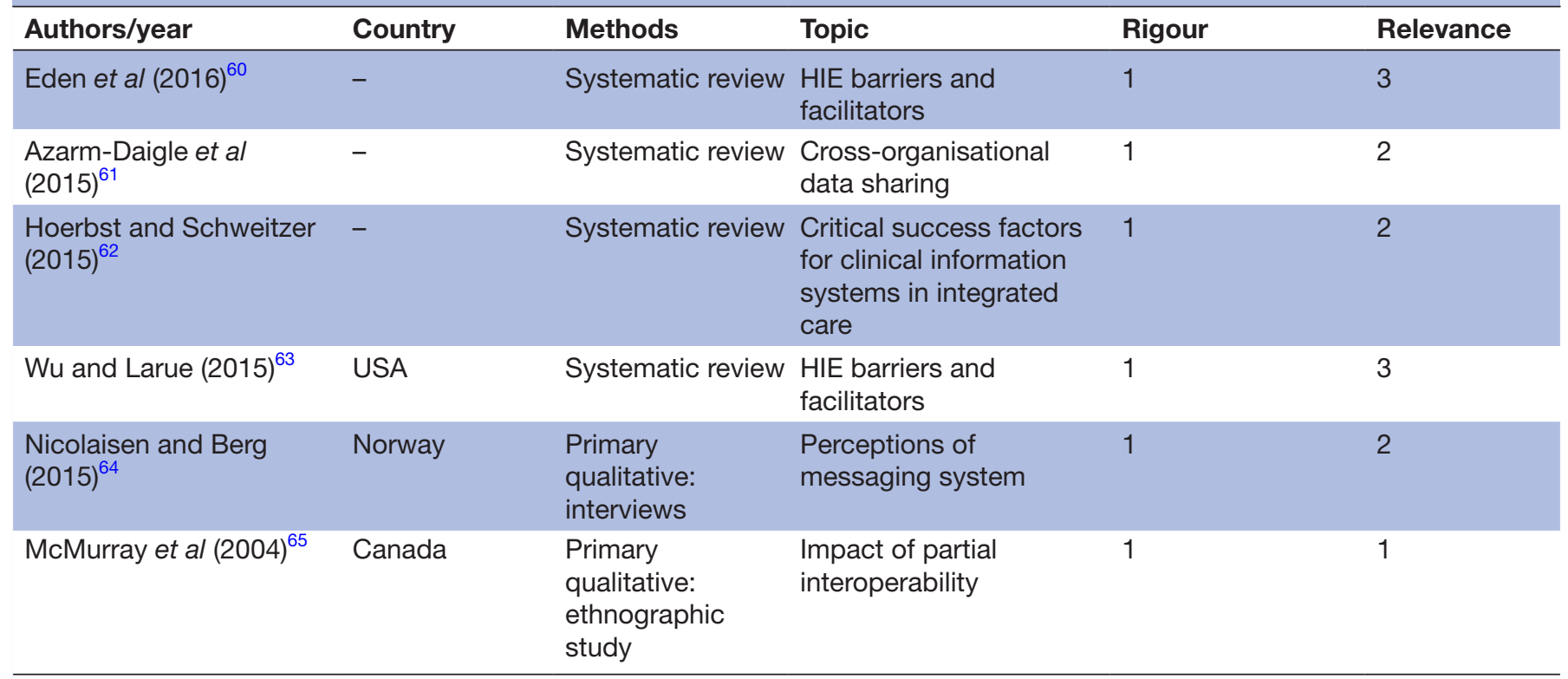

HIE, Health Information Exchange.

adopt different criteria for assessing rigour and relevance. It seems reasonable to hope that their results would be broadly similar: our findings are, for example, consistent with reports of poor user experiences with IT systems in other settings. ${ }^{45}$ But we cannot be sure of this. A fourth limitation is that we did not find studies of fully integrated networks, and so were not able to explore contributions of different network configurations to the observed process and outcome changes.

Technology-driven reasoning, based on the belief that the introduction of new networks will improve clinical processes and outcomes, appears to be widespread. ${ }^{47}$ Our findings point to two problems with the reasoning. First, interoperable networks are usefully thought of as sociotechnical systems, where any effects result from combinations of technologies and users, rather than the technologies alone. ${ }^{49} 50$ Second, policy thinking implicitly assumes that networks will be easy to access and use. Our evidence indicates that this is not the case in practice, with many reports of difficulties. As far as we are able to tell, given sometimes limited information about interventions, all of the reported studies were conducted on functional networks. Clinicians were able to access other organisations' record systems, but had to navigate the different configurations in each one. We suggest that reports of difficulties accessing and using networks are not, therefore, surprising.

We conclude that policymakers and other stakeholders, including clinicians and suppliers, should examine the mechanistic assumptions that underpin current thinking. They should consider focusing on the everyday organisational realities of working across

Table 3 Coordination of services: service and patient outcomes

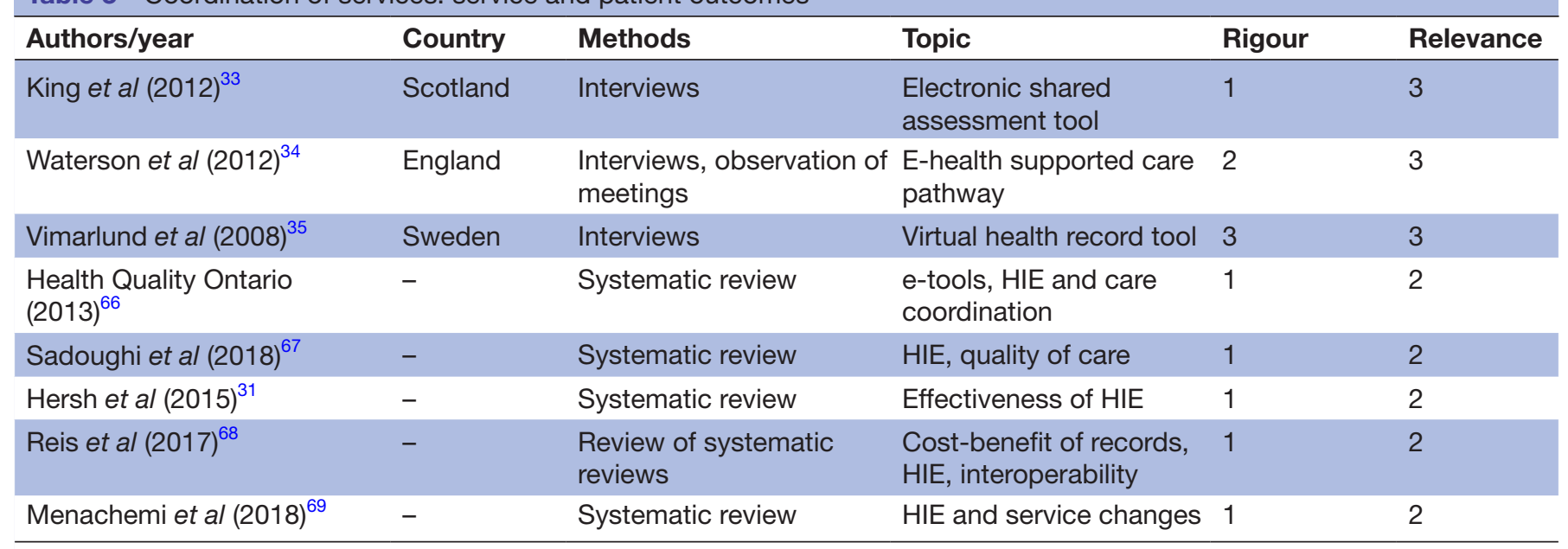

HIE, Health Information Exchange. 
professional and organisational boundaries, and ways in which networks might make it easier for busy clinicians to coordinate their work with one another. Looking ahead, these findings highlight a puzzle about the quality of interoperable networks available to clinicians: there is a need to understand why this continues to be the case. To this end, there is merit in developing policies which set out sociotechnical cases for investments in detail. In addition we, in common with other authors, believe that primary field studies of user experiences of interoperable networks, to identify solutions more acceptable to clinicians, are needed. ${ }^{16}$

\section{Twitter Judy M Wright @jmwleeds and Rebecca Randell @HClforHealthIT}

Acknowledgements We are grateful to the members of the nominal groups, and the PPI panel, for their contributions to the design and conduct of the review.

Contributors PG, JG, JK, RL, RR, JW and JMW developed the proposal for the study. NK and JMW designed and undertook structured database searches. MAA, $J G$ and JK undertook screening and data extraction. PG and JW provided specialist input to the design and interpretation of specific searches. All authors, including SN and CS, contributed to the detailed study design and to the interpretation of overall findings. All authors either drafted or commented on drafts of this article.

Funding National Institute for Health Research-Health Services and Delivery Research programme (project 16/53/03).

Competing interests None declared.

Patient consent for publication Not required.

Ethics approval University of Leeds Faculty of Medicine and Health Ethics Committee (MREC 17-004).

Provenance and peer review Not commissioned; externally peer reviewed.

Data availability statement The majority of material in this article is derived from already published articles and reports. Beyond this, other methods were qualitative and the data generated are not suitable for sharing. Further information can be obtained from the corresponding author.

Open access This is an open access article distributed in accordance with the Creative Commons Attribution 4.0 Unported (CC BY 4.0) license, which permits others to copy, redistribute, remix, transform and build upon this work for any purpose, provided the original work is properly cited, a link to the licence is given, and indication of whether changes were made. See: https://creativecommons.org/ licenses/by/4.0/.

\section{ORCID iDs}

Justin Keen http://orcid.org/0000-0003-2753-8276

Judy M Wright http://orcid.org/0000-0002-5239-0173

Rebecca Randell http://orcid.org/0000-0002-5856-4912

\section{REFERENCES}

1 Stocker R, Bamford C, Brittain K, et al. Care home services at the vanguard: a qualitative study exploring stakeholder views on the development and evaluation of novel, integrated approaches to enhancing healthcare in care homes. BMJ Open 2018;8:e017419.

2 Threapleton DE, Chung RY, Wong SYS, et al. Integrated care for older populations and its implementation facilitators and barriers: a rapid scoping review. Int J Qual Health Care 2017;29:327-34.

3 Institute of Medicine. Health it and patient safety: building safer systems for better care. Washington, DC: National Academies Press (US), 2011.

4 Oliver D FC, Humphries R. Making our health care systems fit for an ageing population. London: The King's Fund, 2014.

5 World Health Organisation,. Medication without harm, 2017.

6 Devine EB, Totten AM, Gorman P, et al. Health information exchange use (1990-2015): a systematic review. EGEMS 2017;5:27.

7 Provonost P JM, Palmer S, Bono R, eds. Procuring interoperability: achieving high-quality, connected and person-centred care. Washington DC: National Academy of Medicine, 2018.

8 Braunstein ML. Health care in the age of interoperability Part 5: the personal health record. IEEE Pulse 2019;10:19-23.
9 Everson J. The implications and impact of 3 approaches to health information exchange: community, enterprise, and vendor-mediated health information exchange. Learn Health Syst 2017;1:e10021.

10 Adler-Milstein J. How to safely make interoperable health information exchange a reality. DePaul L Rev 2019;68:197-208.

11 Bowden T, Coiera E. The role and benefits of accessing primary care patient records during unscheduled care: a systematic review. BMC Med Inform Decis Mak 2017;17:138.

12 Rudin RS, Motala A, Goldzweig CL, et al. Usage and effect of health information exchange: a systematic review. Ann Intern Med 2014;161:803-11.

13 Andreassen HK, Kjekshus LE, Tjora A. Survival of the project: a case study of ICT innovation in health care. Soc Sci Med 2015;132:62-9.

14 Greenhalgh T, Wherton J, Papoutsi C, et al. Beyond adoption: a new framework for theorizing and evaluating Nonadoption, abandonment, and challenges to the scale-up, spread, and sustainability of health and care technologies. J Med Internet Res 2017;19:e367.

15 Williams R. Why is it difficult to achieve e-health systems at scale? Information, Communication \& Society 2016;19:540-50.

16 Fitzpatrick G, Ellingsen G. A review of 25 years of CSCW research in healthcare: contributions, challenges and future Agendas. Comput Supported Coop Work 2013;22:609-65.

17 Wong G, Greenhalgh T, Westhorp G, et al. RAMESES publication standards: meta-narrative reviews. BMC Med 2013;11:20.

18 EUNETHTA. Guideline: process of information retrieval for systematic reviews and health technology assessments on clinical effectiveness. Health Care Germany: Institute for Quality and Efficiency in, 2017.

19 Pawson R. Evidence-based policy. London: SAGE Publications, 2006.

20 Bunn F, Goodman C, Russell B, et al. Supporting shared decision making for older people with multiple health and social care needs: a realist synthesis. BMC Geriatr 2018;18:165.

21 Greenhalgh T, Wong G, Westhorp G, et al. Protocol--realist and meta-narrative evidence synthesis: evolving standards (RAMESES). BMC Med Res Methodol 2011;11:115.

22 Shearn K, Allmark P, Piercy H, et al. Building realist program theory for large complex and messy interventions. Int J Qual Methods 2017;16:160940691774179.

23 Institue of Medicine USA. To Err is Human : Building safer healthcare system in Quality of Health Care in America. Institue of Medicine USA, 1999.

24 Best A, Greenhalgh T, Lewis S, et al. Large-system transformation in health care: a realist review. Milbank Q 2012;90:421-56.

25 Bunn F, Goodman C, Jones PR, et al. Managing diabetes in people with dementia: a realist review. Health Technol Assess 2017;21:1-140.

26 Pollock M WR. Software and organisations. London: Routledge, 2008.

27 Graber ML JD, Bailey R, for US Department of Health and Human Services Office of the National Coordinator for Health Information Technology. Report of the evidence on health it safety and interventions and goals and priorities for health care organizations to improve safety using health IT. Final report. Research Triangle Park, NC: RTI Internatonal, 2016.

28 Wachter R. Making IT work : harnessing the power of health information technology to improve care in England : report of the National Advisory Group on Health Information Technology in England. London, 2016.

29 Marien S, Krug B, Spinewine A. Electronic tools to support medication reconciliation: a systematic review. J Am Med Inform Assoc 2017;24:227-40.

30 Bassi J, Lau F, Bardal S. Use of information technology in medication reconciliation: a scoping review. Ann Pharmacother 2010;44:885-97.

31 Hersh WR, Totten AM, Eden KB, et al. Outcomes from health information exchange: systematic review and future research needs. JMIR Med Inform 2015;3:e39.

32 Zheng K, Abraham J, Novak LL, et al. A survey of the literature on unintended consequences associated with health information technology: 2014-2015. Yearb Med Inform 2016:13-29.

33 King G, O'Donnell C, Boddy D, et al. Boundaries and e-health implementation in health and social care. BMC Med Inform Decis Mak 2012;12:100.

34 Waterson P, Eason K, Tutt D, et al. Using hit to deliver integrated care for the frail elderly in the UK: current barriers and future challenges. Work 2012;41 Suppl 1:4490-3.

35 Vimarlund V, Olve N-G, Scandurra I, et al. Organizational effects of information and communication technology (ICT) in elderly homecare: a case study. Health Informatics J 2008;14:195-210.

36 Kennelty KA, Chewning B, Wise M, et al. Barriers and facilitators of medication reconciliation processes for recently discharged patients 
from community pharmacists' perspectives. Res Social Adm Pharm 2015;11:517-30.

37 Horsky J, Drucker EA, Ramelson HZ. Higher accuracy of complex medication reconciliation through improved design of electronic tools. J Am Med Inform Assoc 2018;25:465-75.

38 Bitan Y, Parmet Y, Greenfield G, et al. The Cognitive Task of Medication Reconciliation - Clinicians' Approaches to the Arrangement of Medical Condition and Medication History Information. Proc Hum Factors Ergon Soc Annu Meet 2016;60:538-40.

39 van Stiphout F, Zwart-van Rijkom JEF, Maggio LA, et al. Task analysis of information technology-mediated medication management in outpatient care. Br J Clin Pharmacol 2015;80:415-24.

40 Vashitz G, Nunnally ME, Parmet Y, et al. How do clinicians reconcile conditions and medications? the cognitive context of medication reconciliation. Cogn Technol Work 2013;15:109-16.

41 Vashitz G, Nunnally ME, Bitan Y, et al. Making sense of diseases in medication reconciliation. Cogn Technol Work 2011;13:151-8.

42 Foged S, Nørholm V, Andersen O, et al. Nurses' perspectives on how an e-message system supports cross-sectoral communication in relation to medication administration: a qualitative study. $J$ Clin Nurs 2018;27:795-806.

43 Fanizza FA, Ruisinger JF, Prohaska ES, et al. Integrating a health information exchange into a community pharmacy transitions of care service. J Am Pharm Assoc 2018;58:442-9.

44 Hohmeier KC, Spivey CA, Boldin S, et al. Implementation of a health information exchange into community pharmacy workflow. J Am Pharm Assoc 2017:57:608-15.

45 Kellermann $\mathrm{AL}$, Jones SS. What it will take to achieve the as-yetunfulfilled promises of health information technology. Health Aff 2013;32:63-8.

46 Gold M, McLAUGHLIN C. Assessing HITECH implementation and lessons: 5 years later. Milbank Q 2016;94:654-87.

47 Wachter R. The digital doctor : hope, hype, and harm at the dawn of medicine's computer age. New York: McGraw Hill Education. Xv, 2015: 1-330.

48 Gawande A. Why doctors hate their computers, in New Yorker. New York, 2018.

49 Mannion R, Davies H. Understanding organisational culture for healthcare quality improvement. BMJ 2018;363:k4907.

50 Exworthy M, Powell M, Glasby J. The governance of integrated health and social care in England since 2010: great expectations not Met once again? Health Policy 2017;121:1124-30.

51 Auschra C. Barriers to the integration of care in Inter-Organisational settings: a literature review. Int J Integr Care 2018;18:5.

52 Allen J, Hutchinson AM, Brown R, et al. User experience and care integration in transitional care for older people from hospital to home: a meta-synthesis. Qual Health Res 2017;27:24-36.

53 Kirst M, Im J, Burns T, et al. What works in implementation of integrated care programs for older adults with complex needs? A realist review. Int J Qual Health Care 2017;29:612-24.
54 Hudson R, Comer L, Whichello R. Transitions in a wicked environment. J Nurs Manag 2014;22:201-10.

55 Goodwin N. Providing integrated care for older people with complex needs lessons from seven international case studies, 2014.

56 Goodwin N, Thiel V, Sonola L, et al. Co-ordinated care for people with complex chronic conditions. The Kings Fund, 2013.

57 Godfrey CM, Harrison MB, Lang A, et al. Homecare safety and medication management with older adults: a scoping review of the quantitative and qualitative evidence. JBI Database System Rev Implement Rep 2013;11:82-130.

58 Tommelein E, Mehuys E, Petrovic M, et al. Potentially inappropriate prescribing in community-dwelling older people across Europe: a systematic literature review. Eur J Clin Pharmacol 2015;71:1415-27.

59 Hernandez J. Medication management in the older adult: a narrative exploration. J Am Assoc Nurse Pract 2017;29:186-94.

60 Eden KB, Totten AM, Kassakian SZ, et al. Barriers and facilitators to exchanging health information: a systematic review. Int J Med Inform 2016;88:44-51.

61 Azarm-Daigle M, Kuziemsky C, Peyton L. A review of cross organizational healthcare data sharing. Procedia Comput $\mathrm{Sci}$ 2015;63:425-32.

62 Hoerbst A, Schweitzer M. A systematic investigation on barriers and critical success factors for clinical information systems in integrated care settings. Yearb Med Inform 2015;10:79-89.

$63 \mathrm{Wu} \mathrm{H}$, Larue E. Barriers and facilitators of health information exchange (HIE) adoption in the United States. Proceedings of the 2015 48th Hawaii International Conference on System Sciences, IEEE Computer Society, 2015.

64 Nicolaisen K, Berg K. Electronic communication across organizational borders in healthcare: an empirical study. UiT Norges arktiske universitet, 2015

65 McMurray R, Cheater FM, Weighall A, et al. Managing controversy through consultation: a qualitative study of communication and trust around MMR vaccination decisions. $\mathrm{Br} J$ Gen Pract 2004;54:520-5.

66 Health Quality Ontario. Electronic tools for health information exchange: an evidence-based analysis. Ont Health Technol Assess Ser 2013;13:1-76.

67 Sadoughi F, Nasiri S, Ahmadi H. The impact of health information exchange on healthcare quality and cost-effectiveness: a systematic literature review. Comput Methods Programs Biomed 2018;161:209-32.

68 Reis ZSN, Maia TA, Marcolino MS, et al. Is there evidence of cost benefits of electronic medical records, Standards, or Interoperability in hospital information systems? overview of systematic reviews. JMIR Med Inform 2017;5:e26.

69 Menachemi N, Rahurkar S, Harle CA, et al. The benefits of health information exchange: an updated systematic review. J Am Med Inform Assoc 2018;25:1259-65. 